\title{
An Approach to an Online EdD in Community College Leadership Program
}

\author{
Christine Harrington (D) \\ New Jersey City University \\ charrington1@njcu.edu
New Jersey City University
ahughes3@njcu.edu
John Melendez (10)
jmelendez@njcu.edu \\ AnnMarie Hughes (D) \\ New Jersey City University
}

\author{
Kimberlee Hooper (D) \\ New Jersey City University \\ khooper@njcu.edu \\ Eric Klein (1) \\ New Jersey City University \\ eklein@njcu.edu \\ Faraz Siddique (1) \\ New Jersey City University \\ fsiddique@njcu.edu
}

\author{
Ellen Wasserman (D) \\ New Jersey City University \\ ewasserman1@njcu.edu
}

\begin{abstract}
The purpose of this article is to provide an example of how an EdD in Community College Leadership program is offered in an online format. First, the benefits of online programs, including increased access and flexibility for working professionals and higher levels of diversity among the student body are discussed. Then, several strategies to promote connection among students and to facilitate a supportive, engaging learning environment virtually are shared. For example, the value of using a cohort model, a carefully designed curriculum with assignments that have practical value, and a balance of synchronous and asynchronous learning activities are described. Finally, the important role of and strategies for incorporating models and mentors into an online doctoral program are discussed.
\end{abstract}

KEYWORDS

online program, cohort, synchronous and asynchronous learning, curriculum

Social justice and equity are core values of doctoral programs that follow the guiding principles of the Carnegie Project on the Education Doctorate (CPED) (n.d.). Toward this end, a diverse student body is essential. However, there is a lack of diversity among the student body in graduate programs. According to 2018 data provided by the National Center for Education Statistics (2020), 63\% of those enrolled in graduate programs in education were White, while only $14 \%$ were Black, and $11 \%$ were Hispanic.

One way to promote equity is by offering online doctoral programs. An online format can provide an inclusionary structure that encourages participation by scholars who represent the varied populations served by community colleges. Increased access to graduate programs is evidenced by the number of students of color who enroll in fully online programs. According to the National Center for Education Statistics (n.d.), the percentage of Black graduate students enrolled in online programs increased more than any other racial group, shifting from only $7.5 \%$ in $2003-2004$ to $45.3 \%$ in 2015 2016. The percentage of Hispanic graduate students enrolled in online programs also increased from $5 \%$ in $2003-2004$ to $31.2 \%$ in 2015-2016. Although the percentage of White students also increased, this increase was not as substantial. In 2003-2004, the percentage of White graduate students in fully online programs was $6.7 \%$ compared to $26 \%$ in $2015-2016$. Thus, online programs seem to be an excellent way to increase the pipeline for diverse educational leaders. According to the National Center for Education Statistics (n.d.), the number of graduate students enrolled in online degree programs in the education field has substantially increased from only $8.2 \%$ in $2003-2004$ to $34.3 \%$ in $2015-2016$. Yet, according to the Carnegie Project on the Education Doctorate (2018) annual report, only $20 \%$ of the EdD programs offered by consortium members of CPED are delivered in an online format.

Increasing the diversity of educational leaders is critical, especially in the community college sector. Students of color are most likely to attend community colleges, yet the faculty and administrative leaders are still predominately White (Dembicki, 2018). Recruiting and supporting doctoral students who are Black and Latinx helps increase and strengthen the pipeline of strong leaders who reflect the diversity of the community college student population. The online Community College Leadership EdD at New Jersey City University $(\mathrm{CCL})$ program has attracted a diverse student
New articles in this journal are licensed under a Creative Commons Attribution 4.0 United States License.

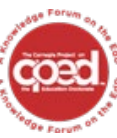

This journal is supported by the Carnegie Project on the Education Doctorate: A Knowledge Forum on the EdD (CPED) cpedinitiative.org 
population. In the CCL program, $48 \%$ of Cohort 1 and $27 \%$ of Cohort 2 are Black and $13 \%$ of Cohort 1 and $14 \%$ of Cohort 2 are Hispanic. The flexibility of the online format can make it easier for diverse working professionals to attend a full-time graduate program. Doctoral programs that are offered in a traditional, face-to-face format add burdens such as travel costs, housing costs, time for travel, and inflexible schedules that can negatively impact students personally and professionally. These barriers may discourage prospective students, especially Black and Latinx students as they are more likely to face multidimensional poverty (Reeves et al., 2016), from applying to the program and thus earning a doctoral degree that is often needed to get their voice at the table for important conversations about supporting community college success. The online CCL program was founded on principles of access and social justice and is devoted to promoting equity for students so they can bring this focus forward in their scholarship and careers.

In addition to the increased likelihood of a racially diverse student body, another benefit of an online program is geographic diversity. Students in the CCL program live in the states of Mississippi, New Jersey, New York, Pennsylvania, Washington, and Wisconsin. Because community college systems vary state by state, having geographic diversity adds tremendous value to the conversations and learning process. An online program provides access for a diverse student body and tremendous flexibility for learning.

Students often find the flexibility of an online program attractive but may have reservations about whether an online program will be engaging and productive. It is common for many students to enter an online program with hesitation about whether this decision will help them achieve their professional goals. Faculty too may be unsure about the effectiveness of an online program. Some educators may question whether online programs develop critical thinking as effectively as in-person courses do. Hermond and Tanner (2020) defined five domains of critical thinking including understanding, judgment, reflection, originality, and caution/skepticism. They conducted a small study of graduate students in Texas to determine the degree to which participants in online graduate courses value critical thinking and the degree to which feel they are developing these skills. Their study found that $80 \%$ of the participants valued critical thinking as essential in their learning process and that the graduate students were quite satisfied with the degree to which they were exposed to the competencies of critical thinking in online courses, with an average score of 4.35 out of 5 on the assessment scale (Hermond \& Tanner, 2020). Rather than an environment of competition and secrecy about research, there is an open and sharing community where cohort members challenge and support one another.

There are several strategies that can make the online learning experience a positive one, perhaps even better than what can be achieved via traditional in-person formats. In the following section, examples of how a CCL program has aimed to engage and support students in a virtual learning environment will be shared. Three aspects of the CCL program will be discussed: the cohort model, curriculum development and delivery, and the use of models and mentors.

\section{THE COHORT MODEL}

The cohort model in educational leadership programs is one that is growing in appreciation throughout the academic world and is especially important in an online EdD program. The cohort model is not new. It has been employed in various educational leadership programs since the 1950s. However, this format has increased in popularity in educational leadership programs as the cohort concept has been shown to enhance interpersonal relationships and individual support in these programs (Barnett et al., 2000). Lovitts and Nelson (2000) pointed out that a key to helping scholars complete a doctorate is to encourage and support a sense of community among doctoral students.

Many students have concerns about whether they will connect to their faculty and classmates in an online learning experience, but the cohort model provides a sense of belonging, comradery, and networking opportunities. Rockinson-Szapkiw et al. (2019) found that students had higher levels of feeling connected and integrated when a cohort model was used. Research suggests that a cohort model increases the number of individuals who complete their degrees and provides a higher rate of continued interaction among members over the duration of their professional careers (Nimer, 2009). The intentional emphasis on personal ownership and agency in a cohort model builds personal investment from the students and mirrors the process of being in the role which they envision post-graduation.

The online modality provides flexibility to adult learners who are often juggling full-time work as well as various personal commitments. An online learning experience provides a level of stability that makes achieving a doctoral degree while balancing work-life commitments more tenable, and the cohort model provides students with a built-in support system. Many students in this EdD program have commented that they sometimes forget this is an online program because they feel so connected to their peers and professors, having several opportunities to engage with them each week when it fits into their schedule. The cohort experience enhances the online learning format by developing a community of learners. The CCL program uses a cohort model with cohort sizes of 21-23. The cohort model was used to support student success by fostering connections among classmates and increasing communication pathways.

\section{Fostering Connections}

Online students face unique barriers in making connections with peers including challenges associated with creating relationships at a distance. Before the start of the CCL program, group collaboration was encouraged through an assigned partner activity, where students had to meet and then introduce a classmate at the first orientation session. This design was an excellent ice breaker and an enjoyable way for students to be introduced to cohort members. During a summer institute, which was held virtually due to the pandemic, students were required to use a Pecha Kucha approach to introduce themselves to the entire group. Pecha Kucha presentations consist of 20 slides that each run only 20 seconds long. The slides contain only graphics and no text. This concise and engaging presentation format was an interesting and effective way for cohort members to learn more about each other. Students were able to share their motivations and experiences with the group, which significantly enhanced the initial bond among cohort members. Through this process, it was discovered that many shared the same 
struggles and motivations to enter the program. Berry (2017) noted that cohort and small group activities can promote a sense of community in online programs.

\section{Communication}

The program was designed from the onset to encourage communication between the cohort through several platforms. Faculty hold monthly virtual meetings and weekly office hours specific to each cohort. Weekly Zoom office hours and meetings are a space for students to connect with cohort members as well as facilitate continued communication with professors. Also, faculty host numerous synchronous sessions on topics related to the courses and overall program. Synchronous sessions are offered at different times on different days to accommodate the varied schedules of students and are recorded for those unable to attend the live sessions.

Throughout the program, students are expected to support one another. In many courses, the students are required to share their work in an online space such as a discussion board so that cohort members can review the work of their colleagues and engage in further dialogue. This approach allows students to benefit from peer conversations and models and in many cases, the students are expected to provide constructive peer feedback to one another.

Students were also encouraged to connect on their own. For example, each cohort was encouraged to set up group messaging, using tools such as What's App, between the cohort members. This provides a space for continued collaboration, encouragement, and support throughout each class. The graduate assistant in the department was also charged with setting up regular informal meetings for cohorts to get together virtually to discuss challenges, share successes, and support one another. Students in the cohorts determine the nature and focus of these meetings. In addition, many students have offered to share their expertise. For example, students who have strong writing skills have provided mini workshops on using APA style and others who have strong quantitative skills have provided support related to statistics and research skills. In the CCL program, some students report logging into informal Zoom meetings with cohort members to work independently on assignments so that they can easily ask a question of a classmate as needed.

\section{CURRICULUM DESIGN AND DELIVERY}

Curriculum design and delivery are always important, but especially so in an online program. This CCL program is outcomesbased and focused on the notion of constructive alignment. Smith and Lovat (2003) defined curriculum as a process of making decisions about educational goals and how best to accomplish them. The constructive alignment refers to the faculty's role in creating a learning environment, incorporating academic assessment, and utilizing pedagogical activities that support the achievement of the desired learning outcomes. A description of the following four curriculum factors will be discussed: using backward design, honoring the varied experiences and talents of students, connecting academia to practice, and the importance of balancing of synchronous and asynchronous learning experiences when delivering curriculum.

\section{Using Backward Design}

Using Wiggins and McTighe's (2005) backward design, the faculty identified program and course-level outcomes that align with what is needed in the field. An advisory board comprised of 18 community college experts from across the nation was created and their input on the essential skills and knowledge needed, along with the competencies outlined by the American Association of Community Colleges (2018), shaped the outcomes that guided the program and curriculum development. The curriculum in the online CCL program provides collective and shared goals for students to discuss and apply innovative ideas to solve problems with multidimensional styles of leadership. Reducing equity gaps and applying social justice is a focus throughout the curriculum. Toward this end, readings and expert guest lecturers have been carefully selected to ensure that the voices of Black, Latinx, and other marginalized populations are heard.

After the program and course outcomes were determined, faculty defined the types of assessments that would demonstrate student achievement of these outcomes. At the program level, a program evaluation dissertation framework was identified as a key assessment. This research approach provides students with the data collection and analysis skills needed to make informed decisions about what programs to support as a leader. In addition to supporting student skill development, this approach also provides a significant benefit to community college partners who may not have the resources for a program evaluation but would find this data incredibly helpful to their work. In this online program, students are encouraged to focus on how to conduct the program evaluation virtually. This enables students to support the work of community colleges across the nation and not be restricted by geography.

At the course level, assignments align with course-level learning outcomes and support the overall program goals and priorities. For example, in the introductory research course, The Scholarly Practitioner, one of the outcomes focuses on students learning to communicate research findings to various community college stakeholders. The assessment is a blog on an identified problem of practice. This assignment directly connects to the scholarly practitioner focus of the program. Formative assessments such as an annotated bibliography and a synthesis matrix have been used to assist students with skill development and to support their success on this summative assessment.

Teaching strategies were then carefully selected to support student success on these formative and summative assessment tasks. For example, in addition to faculty sharing their expertise, a community college expert who writes blogs for Inside Higher Education was invited to conduct a webinar for doctoral students. During this webinar, the presenter shared tips on how to write blogs, the benefits of doing so, and many of the challenges that can be encountered when writing blogs. In addition, faculty invited students to share their drafts, giving and receiving feedback, during Zoom working sessions and via asynchronous online discussions.

\section{Honoring Student Experiences and Talents}

To develop relevant curriculum, faculty need to know who their students are and what they will be bringing to their studies (Lea, 2004). A diverse student body requires increased innovation in the way courses are developed and delivered to meet the demands of different cohorts of students (Gaskell \& Mills, 2014). Toward this end, faculty in the CCL program have spent significant time getting to 
know their students through one-on-one meetings, phone calls, and small and large group discussions. This information is used to assist CCL faculty in identifying partners or group membership for projects, connecting cohort members with similar experiences or interests, and shaping assignments to build and expand on student knowledge and experiences.

The information learned from these meetings also guided faculty in determining what type of support their online learners needed to achieve the course learning outcomes. For example, faculty have asked on and off-campus experts to assist students with developing their library search skills, giving online presentations, and learning how to use online tools such as reference management systems that can help them be more efficient and productive. In some cases, faculty have asked students with expertise in using technology tools to share their knowledge with cohort members during a Zoom meeting or through a recorded instructional video. Sankaran and Bui (2000) proposed that to be able to reap the full benefits of online learning, education needs to match technology with the background and needs of the learners.

\section{Connecting Academia to Practice}

Curriculum in an online program can be designed to provide students with practical opportunities to put theory and research into action. The learning experiences in this CCL program enable students to practice the skills being taught in the program directly in a work setting. For example, during the second year of the program, students participate in an experiential learning program. Thus, the CCL program allows students to work as a thought partner and team member on a project at a community college placement site. This service-learning approach assists students with developing essential leadership skills and content expertise while providing a valuable service to a community college partner. As this is a virtual experience, students can work with colleges across the nation and outside experts can easily provide guidance and support via Zoom meetings. This virtual approach also makes it easier for doctoral students to participate in meetings at the placement site as travel time is not necessary. Many students can use a lunch break to attend virtual Zoom meetings with their colleagues at the community college partner site.

In addition, the program evaluation dissertation requires the student to add knowledge to the field, while concurrently implementing and assessing programs designed to make a positive impact. This has immediate value to the institution where the program evaluation is being conducted as they will be able to use the data to guide decision-making. This program evaluation framework facilitates and challenges future leaders in the cohort to understand their research as it specifically relates to a community college rather than a hypothetical or generalized academic setting. The virtual nature makes it much easier for students to interact with key stakeholders as this eliminates travel time and costs that would often serve as barriers.

\section{Delivering Curriculum: Balancing Synchronous and Asynchronous Experiences}

Curriculum delivery is also important. The CCL doctoral program blends synchronous and asynchronous teaching and learning environments in a way that helps students feel connected to the faculty, content, and each other while not over-taxing students who are working professionals. Research has found that increased opportunities for synchronous learning were associated with higher levels of program integration (Rockinson-Szapkiw et al., 2019). Despite their value, synchronous learning activities can be a challenge for students with inconsistent and busy schedules.

Flexibility is important for students that select an online doctoral program because most are working full-time and assuming responsibilities at home. Rather than having set times where students are required to attend synchronous sessions, the CCL program offers optional synchronous sessions. Sessions are either mid-day when some can use their lunch hour to attend or late afternoon or evening. They are held on different days of the week to accommodate the varied schedules of students. Each semester, students interact with numerous community college leaders such as college presidents, researchers, and authors via these synchronous meetings. These sessions are recorded and shared with those unable to attend. On average, approximately $75 \%$ of the students in the CCL program have attended the live sessions. In addition to cohort and program synchronous sessions, the CCL program faculty have encouraged students to connect regularly with each other using synchronous methods and use this approach for individual and small group meetings with students.

Interaction is a key component in becoming successful. It is important that faculty and students feel a connection to the content of each lesson and each other (Watts, 2016). In the absence of physical interaction, faculty and students must identify creative ways to connect through technology that enables them to contribute to the group dynamic. Research suggests that adult students seek to foster relationships with others and share their expertise in an academic setting (Merrian \& Caffarella, 1999, as cited in Barnett et al., 2000). Technology offers various modes of communication that promote the social element of learning where information sharing can spark ideas and initiate reflective thinking (Watts, 2016). The CCL program offers students a well-balanced mix of interactive synchronous sessions with diverse speakers and topics, and asynchronous discussions that promote expansive thinking and the opportunity to share ideas and experiences. Connecting with faculty and students through discussion boards and group projects fosters the interaction students often crave when trying to be introspective and reflective in an online setting. When online courses and programs were first developed, the primary tool was the discussion board, but with the significant advances in technology, there are numerous ways to engage online learners. Perez et al. (2020) emphasized the significance of interaction in coursework, research, and co-curricular activities on students' perspectives on the relevance of equity, diversity, and inclusion. The online format provides students with numerous ways such as discussion boards, chat, and Zoom to connect with classmates, faculty, and experts in the field.

Incorporating both synchronous and asynchronous teaching and learning strikes an important balance between connection and flexibility. The synchronous sessions in the CCL program offer faculty and students an opportunity to participate in thoughtful dialogues that reflect on readings, apply theories, and incorporate professional experiences, while the asynchronous sessions enable students to process information over time and share insight into the perspectives of themselves and others. Through individual assignments and group work, students collaborate with fellow leaders from diverse backgrounds and cultures while navigating each assignment and building skills that translate back to their professional roles (Lieberman, 2018). The CCL doctoral program 
uses a blend of interactive on- and off-line discussion and collaborative assignments.

\section{MODELS AND MENTORS}

One of the central tenets of the CCL program is that modeling and mentoring are critical to leadership development. Faculty serve as models, which supports student development of essential leadership skills (Cohen et al., 2016). For example, faculty actively engage in professional and public scholarship focused on equity, social justice, and student success. Faculty share this work with their students and often invite students to co-present or co-author papers. Faculty also encourage students to publish on their own (Kezar et al., 2018).

In addition, faculty bring in numerous experts to speak to students about various issues facing the community college sector. In some cases, speakers engage in a discussion with a specific cohort, and in other cases, speakers address all students in the program. Students also get to learn from keynote and breakout session speakers at the annual conference, the Community College Showcase, which is a signature learning experience in the program. The speakers who presented are at the forefront of the community college educational field. The online environment facilitates hosting guest lectures because financial burdens such as travel costs are eliminated. Speaker availability can also be more easily accommodated as lectures do not have to be during a scheduled class time. Varying the days and times works well for speaker and student schedules.

During the experiential learning component of the program which takes place in year two of the program, students are assigned a personal mentor. Faculty have leveraged their professional networks and technology platforms such as Linkedln to connect with experts across the nation who can then serve as mentors. Students benefit from 20 hours with their mentor during this year-long experience. This extensive access to a mentor supports the professional growth of students.

\section{CONCLUSION AND RECOMMENDATIONS}

This online program has aimed to provide the structure, modeling, and support to help diverse doctoral students be successful. In this online environment, relationships have been born, and leadership skills have been developed and tested. Students have been immersed in equitable and academically rigorous work through various online activities and projects that have value today and in the future. The cohort model provides students with a built-in support team of colleagues and faculty members. Students have expanded their knowledge and professional networks through the synchronous meetings with experts in the field and the virtual conferences hosted by the program.

For those interested in creating or enhancing an online experience that is both rewarding and achieves program goals, the following recommendations are offered:

1. Determine what technology platforms will be used and ensure that all students have access to these platforms and know how to use them. Provide live training or recorded online tutorials as needed.

2. Engage students in virtual onboarding activities such as welcome sessions and orientation programs. Consider assigning students to a partner or small group and requiring students to connect prior to the orientation so that they begin to form relationships early on.

3. Offer a combination of synchronous and asynchronous learning experiences so students benefit from both the connection and flexibility offered through each approach. When possible, bring in outside experts to help students build knowledge and expand their professional network.

4. Require a combination of individual, partner, and small group projects so that students have opportunities to engage with other cohort members but also get to immerse themselves in independent reflection and learning too.

5. Determine how to incorporate experiential learning opportunities into the program and provide students with mentors and support related to the project as well as their professional growth.

6. Meet regularly with students individually, in small groups, and as entire cohorts to stay connected and provide support. Relationships matter.

A rigorous online $\mathrm{EdD}$ program can accommodate a diverse array of scholars by eliminating some of the barriers that may prevent potential students from pursuing a doctoral degree. The recommendations provided can assist doctoral coordinators and faculty who are developing new online programs or transitioning face-to-face programs to online programs. When online programs are developed with equity in mind, they can provide potential scholarly practitioners of color with a flexible, supportive learning pathway to become college leaders and serve as champions and role models for community college students.

\section{AUTHOR NOTE}

Email correspondence can be sent to charrington1@njcu.edu, khooper@njcu.edu, ahughes3@njcu.edu, eklein@njcu.edu, jmelendez@njcu.edu, fsiddique@njcu.edu, and ewasserman1@njcu.edu

\section{REFERENCES}

American Association of Community Colleges (2018). AACC competencies for community college leaders. $3^{\text {rd }}$ edition. https://www.aacc.nche.edu/wpcontent/uploads/2018/11/AACC-2018-Competencies_111618_5.1.pdf

Barnett, B. G., Basom, M. R., Yerkes, D. M., \& Norris, C. J. (2000). Cohorts in educational leadership programs: Benefits, difficulties, and the potential for developing school leaders. Educational Administration Quarterly, 36(2), 255-282.

Berry, S. (2017). Student support networks in online doctoral programs: Exploring nested communities. International Journal of Doctoral Studies, 12, 33-48.

Carnegie Project on the Education Doctorate (CPED) (n.d.). The CPED framework. https://cped.memberclicks.net/the-framework

Carnegie Project on the Education Doctorate (2018). 365 days of the Carnegie Project on the Education Doctorate. https://cped.memberclicks. net/assets/resource-center/docs/cped_2018_annual_report_fina.pdf

Cohen, J.B., Gammel, J.A. and Rutstein-Riley, A. (2016). Learning like adults: A hybrid interdisciplinary doctoral program for mid-career professionals. Emerging Directions in Doctoral Education. Innovations in Higher Education Teaching and Learning, 6, 189-205. https://doi.org/10.1108/ S2055-364120160000006032 
Dembicki, M. (2018, March 8). Not as diverse as they should be. Community College Daily. https://www.ccdaily.com/2018/03/not-as-diverse-as-itshould-be/

Gaskell, A., \& Mills, P. (2014). The quality and reputation of open, distance, and e-learning: What are the challenges? Open learning. The Journal of Open, Distance and eLearning, 29, 190-205.

Hermond, D., \& Tanner, T. (2020). Mastering critical thinking competencies in online graduate classes. Administrative Issues Journal: Education Practice, and Research, 10(1), 47-58. DOI:10.5929/2020.10.1.4

Kezar, A. J., Drivalas, Y., \& Kitchen, J. (2018). Envisioning public scholarship for our time: Models for higher education researchers. Stylus Publishing.

Lea, M. R. (2004). Academic literacies: A pedagogy for course design. Studies in Higher Education, 29(6), 739-756.

Lieberman, M. (2018, April 25). Online students don't have to work solo. Inside Higher Ed. https://www.insidehighered.com/digital-learning/article/2018/ 04/25/group-projects-online-classes-create-connections-and-challenge

Lovitts, B., and C. Nelson. 2000. The hidden crisis in graduate education: Attrition from Ph.D. programs. Academe, 86(6): 44-50.

National Center for Education Statistics (2020). Postbaccalaureate enrollment. https://nces.ed.gov/programs/coe/indicator_chb.asp

National Center for Education Statistics (n.d.). Number and percentage of graduate students enrolled in distance education or online classes and degree programs, by selected characteristics: Selected years, 2003-04 through 2015-16. https://nces.ed.gov/programs/digest/d18/tables/dt18_ 311.32.asp

Nimer, M. (2009). The Doctoral cohort model: Increasing opportunities for success.College Student Journal, 43(4), 1373-1379.

Perez, R. J., Robbins, C. K., Harris, L. W., \& Montgomery, C. (2020). Exploring graduate students' socialization to equity, diversity, and inclusion. Journal of Diversity in Higher Education, 13(2), 133-145. doi:10.1037/ dhe0000115

Reeves, R., Rodrigue, E., \& Kneebone, E. (2016). Five evils: Multidimensional poverty and race in America. https://www.brookings.edu/wp-content/ uploads/2016/06/reeveskneebonerodrigue_multidimensionalpoverty_full paper.pdf

Rockinson-Szapkiw, A. J., Holmes, J., \& Stephens, J. S. (2019). Identifying significant personal and program factors that predict online EdD students' program integration. Online Learning, 23(4), 313-335.

Sankaran, S. R., \& Bui, T. (2000). Impact of learning strategies and motivation on performance: A study in web-based instruction. Journal of Instructional Psychology, 28(3), 191-198.

Smith, D. L., \& Lovat, T. J. (2003). Curriculum: Action on reflection (4th ed.). Social Science Press.

Watts, L. (2016). Synchronous and asynchronous communication in distance learning, A review of the literature. The Quarterly Review of Distance Education, 17(1), 23-32.

Wiggins, G., \& McTighe, J. (2005). Understanding by design. Expanded $2^{\text {nd }}$ edition. Pearson 